\title{
Radioimmunoassay of Human Plasma Retinol-Binding Protein
}

\author{
Frank Rees Smith, Amiram Raz, and DeWitt S. Goodman \\ From the Department of Medicine, Columbia University College of Physicians \\ and Surgeons, New York 10032
}

A в S T R A C T A radioimmunoassay for human plasma retinol-binding protein (RBP) has been developed utilizing a double antibody precipitation technique. RBP was purified 1500 - to 2000 -fold by procedures described previously. A specific anti-human RBP antiserum was prepared in rabbits by three once-weekly injections of purified RBP emulsified with Freund's adjuvant. $R B P$ was iodinated with ${ }^{181} \mathrm{I}$ and the $\mathrm{RBP}_{-}{ }^{131} \mathrm{I}$ was purified by gel filtration on Sephadex G-100 after complex formation with human plasma prealbumin. The RBP- ${ }^{131} \mathrm{I}$ was completely $(>95 \%)$ immunoprecipitable in the presence of an excess of specific antiserum, it was not $(<5 \%)$ immunoprecipitable in the absence of specific antiserum, and it could be completely displaced from antibody by excess unlabeled RBP. The standard curve obtained in the immunoassay with normal plasma was identical to that with pure RBP. Duplicate samples differed from their mean by $5 \pm 5 \%$ ( $\pm \mathrm{SD})$. There was a quantitative recovery of pure RBP added in varying amounts to normal plasma. The immunoassay accurately measured RBP in amounts of $10-100 \mathrm{ng}$ per assay tube. There was no significant difference in the immunoreactivity of apo-RBP as compared to holo-RBP. The mean plasma values ( \pm SEM) for a group of 76 normal subjects were $47.2 \pm 1.6 \mu \mathrm{g} / \mathrm{ml}$ for males and $41.6 \pm 1.6$ $\mu \mathrm{g} / \mathrm{ml}$ for females. Plasma RBP levels were markedly depressed $(15 \pm 2.3 \mu \mathrm{g} / \mathrm{ml})$ in 14 patients with acute viral hepatitis. There was a highly significant correlation between the plasma levels of RBP and of vitamin $A$ in both normal subjects and patients with hepatitis. In all subjects plasma $R B P$ was generally saturated $w i^{+} h$ retinol. The data suggest that under normal circumstances RBP circulates almost exclusively as the holoprotein.

Doctors Smith and Raz were Trainees under Grants T1-AM-05397 and T1-AM-05234 during this work.

Dr. Goodman is a Career Scientist of the Health Research Council of the City of New York under Contract I-399. Received for publication 13 May 1970.

\section{INTRODUCTION}

Vitamin A circulates in human plasma as retinol bound to a specific protein, retinol-binding protein (RBP), which has been isolated and characterized recently in this laboratory (1). This protein has $\alpha_{1}$-mobility on electrophoresis, a molecular weight of approximately 21,000 , and a single binding site for one molecule of retinol. In plasma, RBP circulates together with plasma prealbumin (PA), as a protein-protein complex. Previously, on the basis of the content and recovery of protein-bound retinol during RBP purification, it was suggested that the usual concentration of RBP in plasma is of the order of $30-40 \mu \mathrm{g} / \mathrm{ml}$ of plasma (1).

We report the development of a radioimmunoassay for RBP in human plasma. With this imunoassay, the level of RBP in a series of normal subjects and of patients with hepatitis has been determined. The correlation between plasma $\mathrm{RBP}$ and vitamin $\mathrm{A}$ levels has also been examined.

\section{METHODS}

Purification of RBP. RBP and PA were isolated from whole human plasma (usually obtained as outdated plasma from the blood bank) by the following sequence of procedures: chromatography on DEAE-Sephadex, gel filtration on Sephadex G-200, repeat DEAE-Sephadex chromatography, preparative polyacrylamide gel electrophoresis, and gel filtration on Sephadex G-100. These procedures have been described in detail in our previous publications (1-3).

Preparation of antisera. A solution of RBP, $6 \mathrm{mg} / \mathrm{ml}$ in

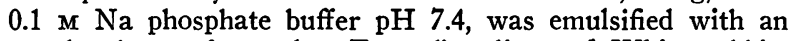
equal volume of complete Freund's adjuvant. ${ }^{1}$ White rabbits weighing approximately $2 \mathrm{~kg}$ were injected three times, at weekly intervals, with $0.4 \mathrm{ml}$ of the emulsified RBP (0.1 $\mathrm{ml}$ per toe pad). 1 month after the first injection the animals were exsanguinated by cardiac puncture; after clotting, the blood samples were centrifuged at $2000 \mathrm{rpm}$ for $30 \mathrm{~min}$ at $4^{\circ} \mathrm{C}$ and the sera were collected. The serum from the animal with the highest titer against RBP (precipitin line by immunodiffusion (4) against a $1: 8$ dilution of normal plasma) was used in the immunoassay.

A control antiserum was prepared by injecting rabbits in a similar fashion with human $\alpha_{1}$-acid glycoprotein puri-

${ }^{1}$ Difco Laboratories, Detroit, Mich. 


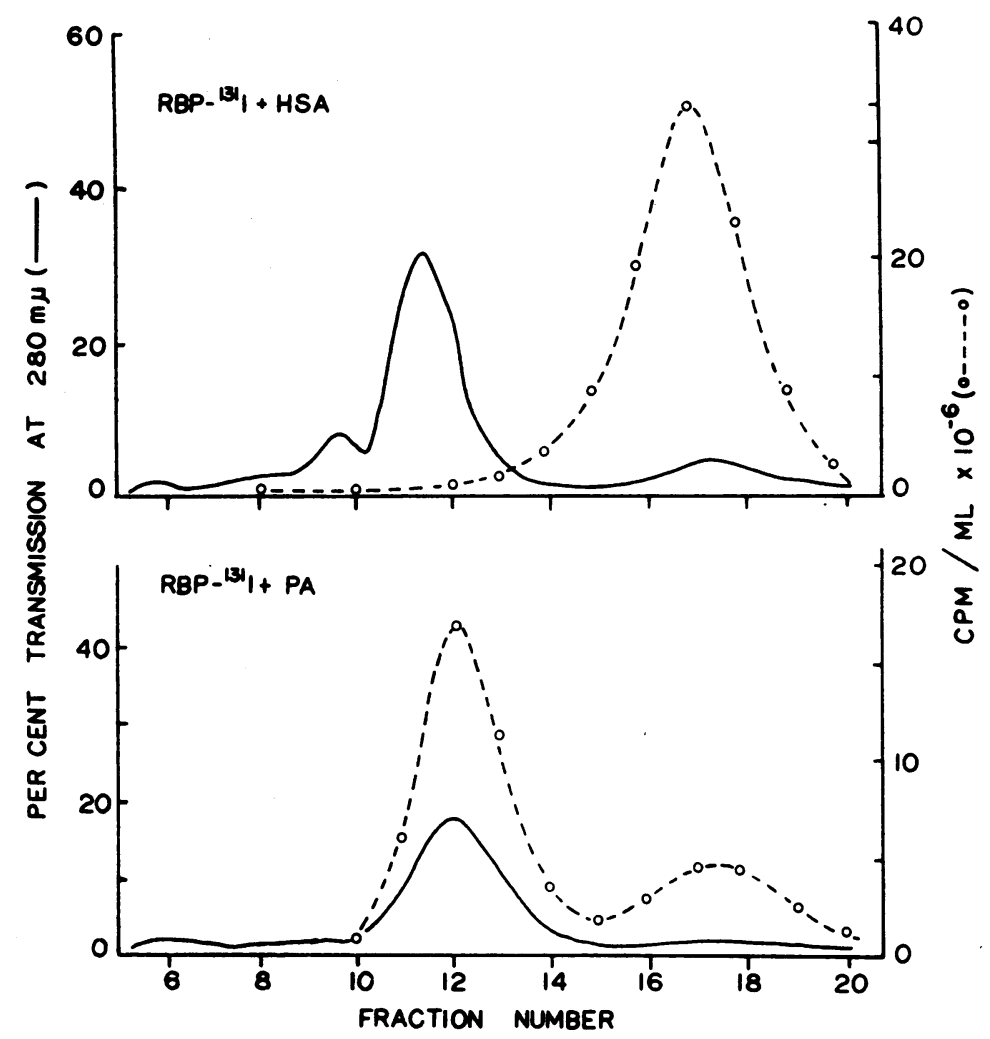

FIGURE 1 Purification of RBP-131 I by gel filtration on columns of Sephadex G-100, first together with human serum albumin (HSA, top panel), and then together with prealbumin (bottom panel). See text for details.

fied in our laboratory (2). This antiserum showed precipitin lines on immunodiffusion when tested against human $\alpha_{1}$-acid glycoprotein or human serum albumin. The antiserum showed no precipitin lines when tested against purified RBP.

Iodination; purification of $R B P_{-}{ }^{131} I . \quad \mathrm{RBP}$ was iodinated with ${ }^{131} \mathrm{I}$ using the IC1 method of McFarlane (5) as modified by Waldmann. ${ }^{2}$ Lyophilized RBP $(1 \mathrm{mg}$ ) was dissolved in $1 \mathrm{ml}$ of $0.4 \mathrm{M} \mathrm{Na}$ borate buffer $\mathrm{pH} 8.0$ and added to a vial containing high specific activity $(35-50 \mathrm{mCi} / \mu \mathrm{g})$ carrier-free $\mathrm{Na}^{-131} \mathrm{I}^{3}$ previously mixed with an equal volume of $0.1 \mathrm{~N} \mathrm{HCl} .0 .033 \mathrm{M}$ IC1 was diluted $1: 10$ with $2 \mathrm{M} \mathrm{NaCl}$. An amount of the dilute IC1 solution (usually $60 \mu 1$ ) was then added to the vial so as to approximate an equimolar ratio between ${ }^{131} \mathrm{I}$ and $\mathrm{RBP}$ assuming a $20 \%$ efficiency of iodination. The observed efficiency of iodination as calculated from recovery of ${ }^{131} \mathrm{I}$ as labeled RBP after purification was usually close to $35 \%$. Immediately after adding the IC1, the solution was mixed and applied to a Sephadex G-50 column $(16 \times 0.8 \mathrm{~cm})$ previously washed with $20 \mathrm{ml}$ of human serum albumin $(1.2 \mathrm{mg} / \mathrm{ml})$ in $0.4 \mathrm{M} \mathrm{Na}$ borate buffer $\mathrm{pH}$ 8.0. The proteins were eluted with borate buffer at room temperature; fractions of $0.5 \mathrm{ml}$ were collected in vials containing $4 \mathrm{mg}$ of human serum albumin each and

\footnotetext{
${ }^{2}$ Waldmann, T. A. Personal communication.

${ }^{3}$ Iso/Serve, Cambridge Nuclear Corp., Cambridge, Mass.

* Proserum, Dow Chemical Co., Midland, Mich.
}

then assayed for ${ }^{131} \mathrm{I}$. The major portion of the radioactivity was eluted with RBP immediately after the void volume. RBP- ${ }^{131}$ I was purified by gel filtration on Sephadex G-100 before and after complex formation with PA. The fractions from the Sephadex G-50 column containing the first half of the RBP- ${ }^{131}$ I peak (approximately $0.5 \mathrm{mg}$ of $\mathrm{RBP}$ in $2 \mathrm{ml}$ ) were pooled and were then chromatographed on a Sephadex G-100 column $(80 \times 1.4 \mathrm{~cm})$ at $4^{\circ} \mathrm{C}$, using $0.02 \mathrm{M} \mathrm{K}$ phosphate $\mathrm{pH} 7.4$ containing $0.2 \mathrm{M} \mathrm{NaCl}$ as eluting buffer, with a flow rate of $15 \mathrm{ml} / \mathrm{hr}$. The effluent was monitored continuously at $280 \mathrm{~nm}$ with an $\mathrm{LKB}^{5}$ Uvicord II absorptiometer; fractions of $6 \mathrm{ml}$ were collected and assayed for ${ }^{181} \mathrm{I}$. Radioactivity was recovered in an effluent volume characteristic of RBP (molecular weight approximately 21,000) (Fig. 1, top). The fractions containing RBP-181I (fractions 15-19 of Fig. 1, top) were pooled and concentrated to $2 \mathrm{ml}$ by ultrafiltration using an Amicon ${ }^{6} \mathrm{UM}-1$ filter. Lyophilized human prealbumin, $4 \mathrm{mg}$, was dissolved in the RBP-19I solution; after $15 \mathrm{~min}$ at room temperature, the solution was chromatographed on a column of Sephadex G-100 of similar size and under identical conditions. $65-74 \%$ of the radioactivity was now eluted in a volume characteristic of the RBP-PA complex (Fig. 1, bottom, fractions 10-14). The solution of purified RBP-181 (in the form of a complex with PA) was stored in the dark at $-20^{\circ} \mathrm{C}$ until used.

${ }^{5}$ LKB Instruments, Inc., Rockville, Md.

${ }^{\mathrm{B}}$ Amicon Corp., Lexington, Mass. 


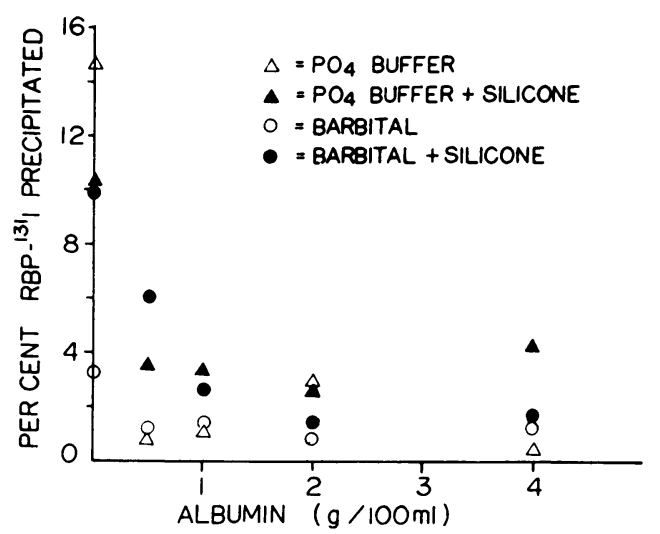

FIgURE 2 Effect of assay conditions on the precipitation of $\mathrm{RBP}^{131} \mathrm{I}$ in the absence of anti-human RBP antiserum. $0.05 \mathrm{M} \mathrm{Na}$ barbital buffer $\mathrm{pH} 8.5$ in glass tubes, $\mathrm{O} ; 0.05 \mathrm{M}$ barbital $\mathrm{pH} 8.5$ in siliconized tubes, $0 ; 0.05 \mathrm{M} \mathrm{K}$ phosphate buffer $\mathrm{pH} 7.7$ in glass tubes, $\triangle ; 0.05 \mathrm{~m}$ phosphate $\mathrm{pH} 7.7$ in siliconized tubes, $\boldsymbol{\Delta}$.

Studies carried out after the development of the radioimmunoassay procedure demonstrated that an equivalent purification of the RBP- ${ }^{131}$ I could be achieved by omission of the first Sephadex G-100 gel filtration (of RBP- ${ }^{131} \mathrm{I}$ plus serum albumin). In most of the studies reported here the usual procedure was to carry out a single Sephadex G-100 chromatography after complex formation between the labeled RBP and PA.

Immunoassay procedure. A radioimmunoassay was developed using a double antibody precipitation technique, generally similar to the method of Morgan and Lazarow for the immunoassay of insulin (6). Incubation conditions were selected to reduce the nonspecific precipitation of RBP_si I observed in the absence of the specific antiserum against RBP. With $0.05 \mathrm{M}$ barbital buffer $\mathrm{pH} 8.5$ containing $1 \%$ human or bovine serum albumin in untreated glass test tubes, the nonspecific $\mathrm{RBP}^{101}$ I precipitation was $1 \%$ (Fig. 2) and this was chosen as the buffer system (designated barbitalalbumin buffer).

In each assay, $0.1 \mathrm{ml}$ of diluted rabbit antiserum (including both the specific anti-RBP and the control antisera) was added to a $75 \times 10 \mathrm{~mm}$ disposable test tube, followed in order by standard RBP or human plasma diluted in barbitalalbumin buffer, barbital-albumin buffer alone, and finally RBP- ${ }^{131} \mathrm{I}$; the final volume of the assay mixture was $0.5 \mathrm{ml}$. The sequence of adding reagents was always the same. The mixture of anti-RBP antiserum and control antiserum was usually prepared so that the final dilution of the anti-RBP antiserum in the assay tube was $1: 500$ to $1: 600$, whereas the final dilution of the control antiserum was $1: 40$. This amount of control antiserum was added in order to ensure uniform and nearly complete recovery of rabbit gamma globulin in the final precipitate. The total amount of rabbit gamma globulin was identical in all samples. At this dilution of the anti-RBP antiserum, $50-60 \%$ of the RBP${ }^{191}$ I was usually antibody bound in the absence of added unlabeled RBP. After preparing the assay mixtures, the tubes were put in the dark at $4^{\circ} \mathrm{C}$ for overnight $(18 \mathrm{hr})$ incubation. In the morning $0.1 \mathrm{ml}$ of anti-rabbit gamma globulin antiserum, made in goats, ${ }^{7}$ was added to each tube, and

${ }^{7}$ Pentex Biochemical, Kankakee, Ill. the tubes were mixed and returned to the dark at $4^{\circ} \mathrm{C}$ for $135 \mathrm{~min}$; the second incubation produced a nearly quantitative precipitation of rabbit gamma globulin. After the second incubation, the precipitates were collected by centrifugation at $4^{\circ} \mathrm{C}$ for $15 \mathrm{~min}$ at $17,300 \mathrm{~g}$ in a Sorvall model $\mathrm{RC}-2 \mathrm{~B}$ centrifuge. The supernatant solutions were removed, the precipitates washed with $0.5 \mathrm{ml}$ of barbital-albumin buffer, and the wash and supernatant solutions combined. The samples were then assayed for ${ }^{131} \mathrm{I}$ in a Packard autogamma spectrometer. In the assay, ${ }^{131} \mathrm{I}$ found in the precipitate represented antibody-bound $\mathrm{RBP}^{131} \mathrm{I}$, whereas ${ }^{131} \mathrm{I}$ in the supernatant-wash solution represented free (i.e. not bound to antibody) RBP. After radioassay, the bound/free ratio of RBP- ${ }^{131} \mathrm{I}$ was calculated for each sample, and the amount of RBP in the assay tube was then determined from the standard curve for that experiment.

Immunoassay controls. In each set of assays, tubes were included in which $(a)$ the specific anti-RBP antiserum was used at a final dilution of $1: 40$ (without the addition of control antiserum) (b) the specific anti-RBP antiserum was omitted from the assay mixture (control antiserum alone at a final dilution of $1: 40$ ), and (c) a large excess (1-5 $\mu \mathrm{g}$ ) of unlabeled RBP was added to the usual assay mixture.

$R B P$ standard. A solution of purified RBP, 200-300 $\mu \mathrm{g} / \mathrm{ml}$ in $\mathrm{H}_{2} \mathrm{O}$, was kept frozen in the dark. Just before use the solution was thawed; an amount containing $10 \mu \mathrm{g}$ of $\mathrm{RBP}$ was removed, mixed with a solution containing $40 \mu \mathrm{g}$ of purified PA, and then adjusted to $1.0 \mathrm{ml}$ volume with barbital-albumin buffer. This solution of RBP $(10 \mu \mathrm{g} / \mathrm{ml})$ was diluted serially with barbital-albumin buffer to concentrations of $1 \mu \mathrm{g} / \mathrm{ml}$ and $0.1 \mu \mathrm{g} / \mathrm{ml}$ and these solutions were used to determine the standard curve. The concentration of RBP in the stock standard solution was checked each time before making the first dilution by determining the ultraviolet absorption spectrum of the solution. A standard curve was determined with each set of assays and was used to calculate the levels of RBP in that particular set of samples. Later experiments have shown that the addition or omission of purified PA to the purified RBP does not affect the values obtained in the standard curve.

Plasma samples. Samples were obtained from men and women with normal medical histories and physical examinations. Female subjects were not taking contraceptive medication. 7-15 ml of blood was collected in heparinized vacutainer tubes ${ }^{8}$ and the plasma was separated by centrifugation at $4^{\circ} \mathrm{C}$, frozen, and stored in the dark. Before use the samples were thawed and diluted $1: 100$ to $1: 200^{\circ}$ with barbital-albumin buffer. Plasma dilutions were selected so that the bound/free ratios for RBP-131I fell on the most sensitive portion of the standard curve (see below). Samples of plasma were obtained also from 14 patients with acute viral hepatitis during the early phase of their illness (mean plasma bilirubin, $11.9 \mathrm{mg} / 100 \mathrm{ml}$; serum glutamic oxaloacetic transaminase [SGOT], $1613 \mathrm{mU} / \mathrm{ml}$; and alkaline phosphatase, $162 \mathrm{mU} / \mathrm{ml}) .^{9}$ The samples were prepared and assayed in the same manner as those from normal subjects.

$V$ itamin $A$ determinations. Plasma vitamin A levels were measured by the trifluoroacetic acid method of Dugan, Frigerio, and Siebert (7) as modified by Roels and Mahadevan (8).

Statistics. Correlation coefficients were calculated on an Olivetti Programma $101^{10}$ using a program prepared for this

\footnotetext{
${ }^{8}$ Becton-Dickinson \& Co., Rutherford, N. J.

${ }^{8}$ Normal SGOT $10-50 \mathrm{mU} / \mathrm{ml}$ and alkaline phosphatase $30-85 \mathrm{mU} / \mathrm{ml}$.

${ }^{10}$ Olivetti Underwood Corp., New York.
} 
instrument (9). Significance was assessed as outlined by Snedecor and Cochran (10).

\section{RESULTS}

Anti-human RBP antiserum. The antiserum obtained from rabbits which had been injected with purified RBP gave a single precipitin line when tested against purified RBP by either immunodiffusion (4) or immunoelectrophoresis (11). When the antiserum was tested against normal human whole plasma, however, three precipitin lines were obtained. The major line showed a reactionof-identity with the single line obtained with purified $\mathrm{RBP}$; one of the two minor lines was identified as immunoprecipitated human serum albumin. The antiserum thus contained antibodies against two human plasma proteins in addition to those against RBP. The presence of these additional antibodies in the antiserum in no way interfered with the precision and specificity of the RBP radioimmunoassay since the antiserum showed only a single line against purified RBP and since the ${ }^{131}$ I label was attached only to purified RBP. This particular antiserum was used in the studies reported here.

More recently, a pure anti-human RBP antiserum was prepared by rechromatography of purified $\mathrm{RBP}$ on a column of Sephadex G-100, before the preparation of the RBP-Freund's adjuvant emulsion and immunization of rabbits as described above. A single precipitin line was obtained by testing this antiserum against whole plasma, and this line showed a reaction-of-identity with the line obtained by reacting this antiserum against purified RBP (Fig. 3).

Standard curve. Fig. 4 shows the curve describing the displacement of $\mathrm{RBP}_{-}{ }^{131} \mathrm{I}$ from antibody by increasing amounts of unlabeled pure RBP. The curve was sigmoid in appearance on a semilogarithmic plot, with the most sensitive portion of the curve corresponding to the addition of $10-50 \mathrm{ng}$ of RBP per assay tube.

Assay of human plasma. Plasma from a single subject was diluted $1: 10$ and $1: 100$ with barbital-albumin buffer and assayed at various dilutions simultaneously with standard RBP. As shown in Fig. 4, the immunoassay curve obtained with whole plasma was identical in shape with the curve obtained with pure RBP. This demonstrated that RBP in whole plasma displaced RBP- ${ }^{181} \mathrm{I}$ from antibody in a manner which was quantitatively identical to the displacement obtained with purified RBP.

Recovery of $R B P$. Normal plasma was diluted with barbital-albumin buffer to concentrations of approximately 9-15 ng of RBP per $0.1 \mathrm{ml}$. Pure RBP was diluted to concentrations of 0.1 and $1.0 \mu \mathrm{g} / \mathrm{ml}$, and portions of these solutions were added to the plasma samples so as to enrich the RBP content by eight amounts ranging from increments of 10 to $250 \%$. Each sample was then assayed in triplicate. The mean recovery \pm SEM of

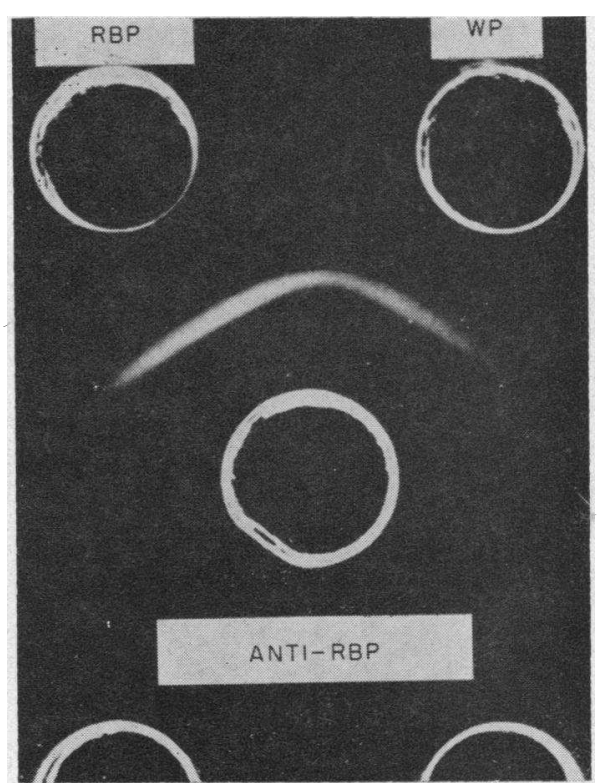

Figure 3 Immunodiffusion study of rabbit anti-human RBP antiserum against purified RBP and human whole plasma (WP).

the pure RBP added to the plasma samples was 104 $\pm 2.2 \%$. The recovery of pure $\mathrm{RBP}$ in the assay was determined by subtracting the RBP values obtained with plasma alone from the values obtained with the samples enriched with known amounts of pure RBP.

Immunoassay controls. When a relatively large amount (dilution 1:40) of specific anti-RBP antiserum was added to the assay tube, $95-100 \%$ of the added ${ }^{181} \mathrm{I}$ was recovered in the immunoprecipitate. This demonstrated that the ${ }^{121} \mathrm{I}$ label was virtually completely attached to immunoreactive RBP and that no "damage" to the labeled antigen had occurred during the first incubation. In contrast, when the specific anti-RBP antiserum was omitted from the assay, less than $5 \%$ of the ${ }^{131} \mathrm{I}$ was found in the precipitate. Finally, more than $95 \%$ of the $\mathrm{RBP}^{131} \mathrm{I}$ could be displaced from the specific antibodies by the addition of $2 \mu \mathrm{g}$ of unlabeled pure RBP. These results established the specificity of the radioimmunoassay for RBP, and such controls were run with each set of assays. If the control values differed from those just described, the assay results obtained in that experiment were discarded.

Intra-assay (within assay) agreement. Plasma samples were routinely assayed in duplicate, and the mean of the pair of values taken as the final value. During an 8 month period the values for duplicate assays on 73 samples from normal subjects differed from the mean value for each duplicate pair by an average of $5.4 \pm 5.0 \%$ $( \pm \mathrm{sD})$. On the basis of these data, the results for a sample were discarded when duplicate assays differed 


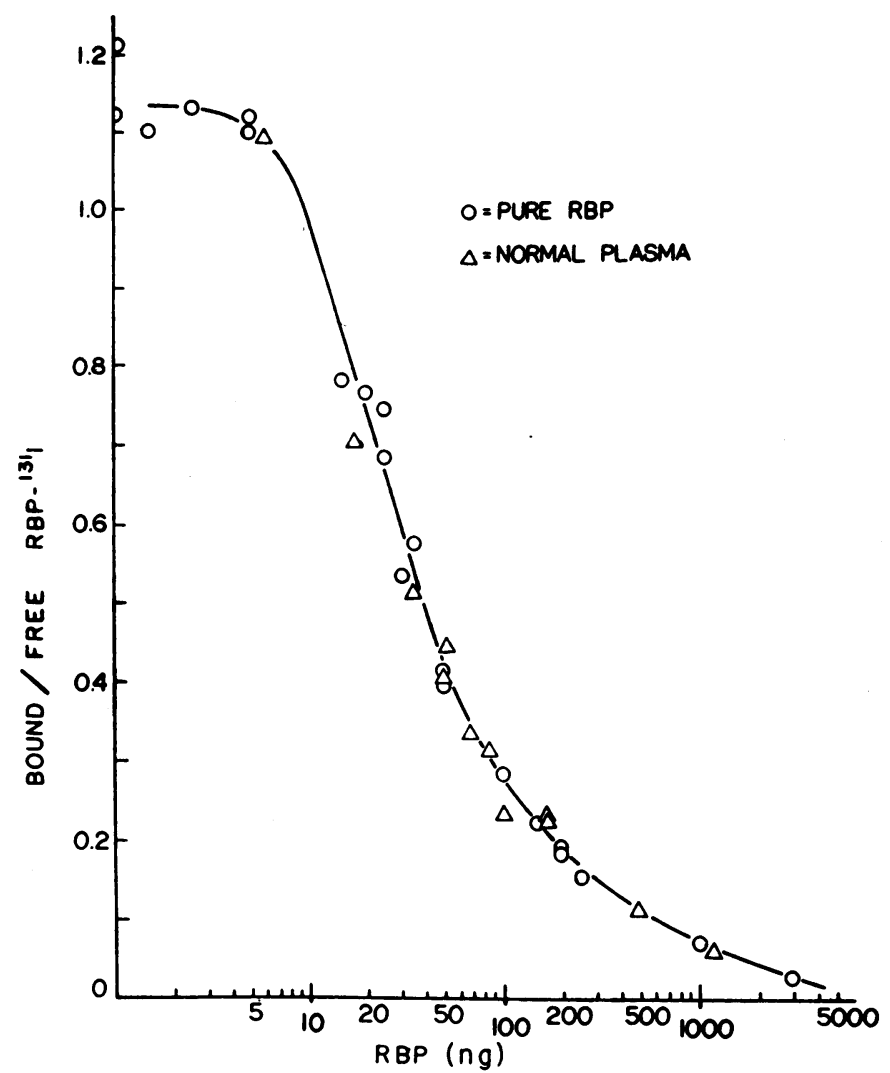

Figure 4 The RBP radioimmunoassay standard curve. The figure demonstrates the displacement of RBP-131 I from antibody by purified RBP and by dilutions of normal plasma. The points for normal plasma were determined by first calculating the mean value for the level of $\mathrm{RBP}$ in the sample of plasma from the several assays carried out on that sample. The expected amount of RBP added per assay tube was then calculated from the amount of diluted plasma added. In the figure these values for RBP are plotted against the observed bound/free ratios for the corresponding samples.

from each other by more than $20 \%$, and the assay of that sample was repeated.

Interassay (between assay) agreement. A sample of plasma from a single subject was divided into $2-\mathrm{ml}$ portions and stored frozen and in the dark. During a 6 month period, portions were assayed in duplicate in 14 different sets of assays. The mean value \pm SD for the sample was $47.1 \pm 3.8 \mu \mathrm{g}$ of RBP per $\mathrm{ml}$.

Assay of lipoproteins and of proteins with density $(D)>1.21$. Since retinol is a lipid-soluble vitamin, the question arose as to whether there might be any immunologic cross-reactivity between RBP and the lipoproteins responsible for the transport in plasma of most of the other plasma lipids. Plasma samples from three subjects were adjusted to a hydrated density of 1.21 by the addition of solid $\mathrm{KBr}$, and the lipoproteins were separated en bloc by ultracentrifugation for $40 \mathrm{hr}$ at
$114,000 \mathrm{~g}$ (12). The lipoprotein $(\mathrm{D}<1.21)$ and the $\mathrm{D}>1.21$ protein fractions were dialyzed overnight against isotonic $\mathrm{NaCl}$. Immunoassay for $\mathrm{RBP}$ of the lipoprotein samples, at a concentration 1.5 times that found in whole plasma, revealed no immunoreactivity. The $D>1.21$ protein fractions, in contrast, were fully immunoreactive, with complete recovery of the RBP immunoreactivity found in the unfractionated whole plasma. These latter results were expected since RBP has a hydrated density greater than 1.21 (1).

Comparison of holo-with apo-RBP and of $R B P$ subspecies. Purified RBP as isolated in our laboratory is microheterogeneous on disc-gel electrophoresis and consists of three bands, two fluorescent and one nonfluorescent, all with $\alpha_{1}$-mobility (3). Evidence has been presented (3) which suggests that during purification the naturally-occurring form of $\mathrm{RBP}$ ("H2" form) is gradu- 
ally converted to a more rapidly migrating form of the holoprotein ("H1") and, in turn, to the retinol-free apoprotein ("A" form).

Two experiments were carried out in order to com. pare the immunoreactivity of holo-RBP with that of apoRBP and of the different RBP subspecies with each other. In the first experiment a sample of purified RBP was largely converted from holo-RBP to apo-RBP by extraction of the protein-bound retinol into heptane (13). The absorbance ratio $(330 \mathrm{~nm} / 280 \mathrm{~nm})$ of the solution of RBP was 0.79 before extraction and 0.16 after extraction, indicating that $80 \%$ of the protein-bound retinol had been extracted into heptane. Portions of the unextracted (mainly holo) and of the extracted (mainly apo) RBP samples were assayed simultaneously, and the results are shown in Fig. 5. There was no significant difference in the immunoreactivity of the two preparations.

In the second experiment, the immunoreactivity of a sample of RBP consisting of a mixture of all three bands (mainly "H2" + "H1") was compared with the immunoreactivity of samples of the almost pure " $A$ " and "H1" forms, respectively (see disc-gel patterns Nos. 1,2 , and 3 in Fig. 2 of reference 3 for the appearance on electrophoresis of the three samples). The " $A$ " and "H1" samples were prepared by repeat preparative

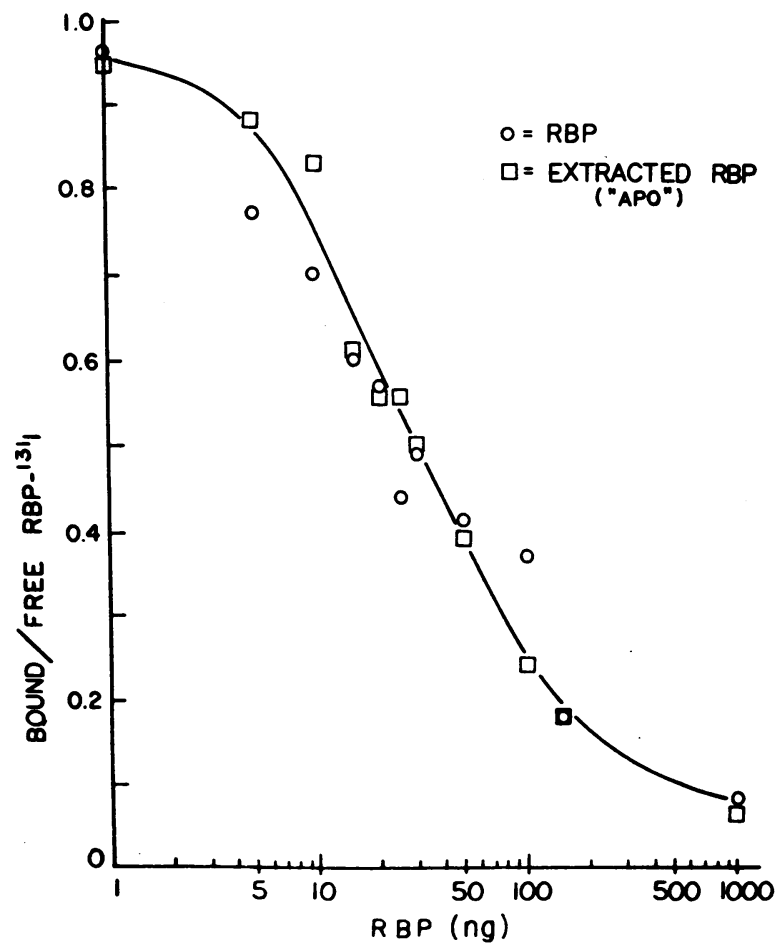

FIGURE 5 Displacement of RBP- ${ }^{181} I$ from antibody by purified (mainly holo) RBP and by extracted (apo) RBP.
$\Delta$

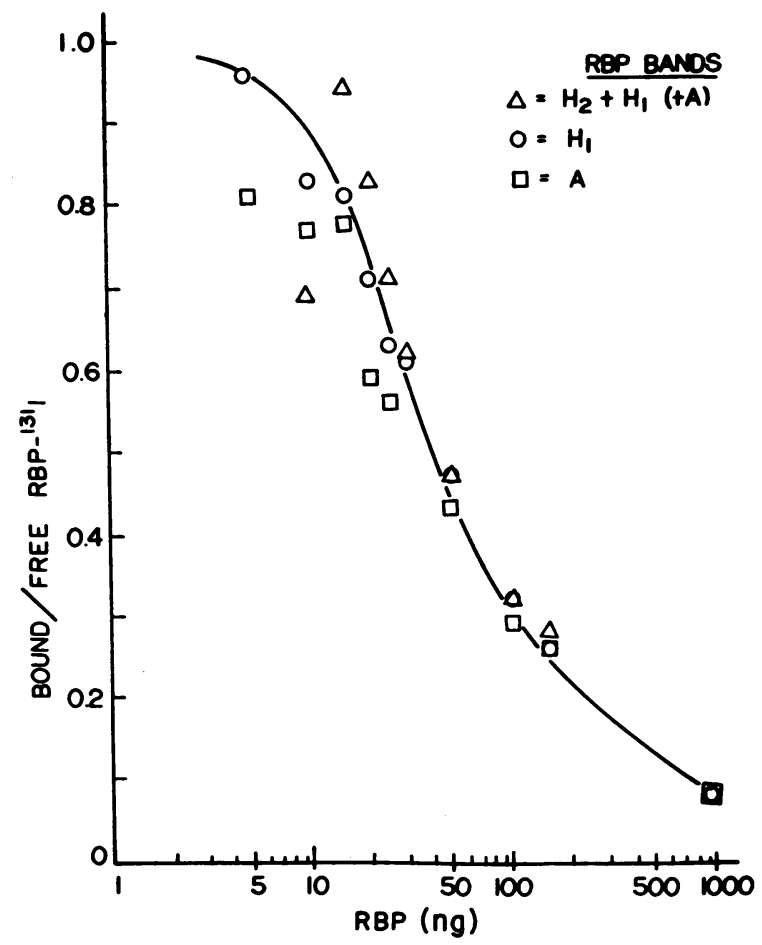

FIGURE 6 Displaciement of RBP-1⿴I from antibody by different RBP subspecies.

polyacrylamide-gel electrophoresis of a sample of purified RBP (3). It should be noted that we have previously shown that the "A" and "H1" forms (previously designated $\mathrm{RBP}_{a}$ and $\mathrm{RBP}_{\mathbf{k}}[1]$ ) have identical amino acid compositions. The results shown in Fig. 6 indicate that the different RBP subspecies have similar immunoreactivities in the immunoassay.

Plasma RBP levels. The mean plasma RBP level $( \pm \mathrm{sD})$ for 38 normal male subjects was $47.2 \pm 9.6 \mu \mathrm{g} /$ $\mathrm{ml}$ and for 38 normal females was $41.6 \pm 10.0 \mu \mathrm{g} / \mathrm{ml}$. There was no correlation between plasma RBP concentration and age in either group. The plasma RBP level was markedly depressed in the 14 samples from patients with acute viral hepatitis $(14.9 \pm 8.3 \mu \mathrm{g} / \mathrm{ml}$, mean $\pm \mathrm{SD})$. Fig. 7 shows the plasma levels of RBP and of vitamin A for the normal subjects and the patients with hepatitis.

Correlation of $R B P$ and vitamin $A$. The level of plasma RBP was significantly correlated with the level of plasma vitamin A in both the group of 76 normal subjects $(r=0.382, P<0.001)$ and the group of 14 patients with hepatitis $(r=0.745, P<0.003)$. Fig. 7 shows the regression line for the combined values from both the normal and the hepatitic subjects $(r=0.692$, $P<0.001)$. 


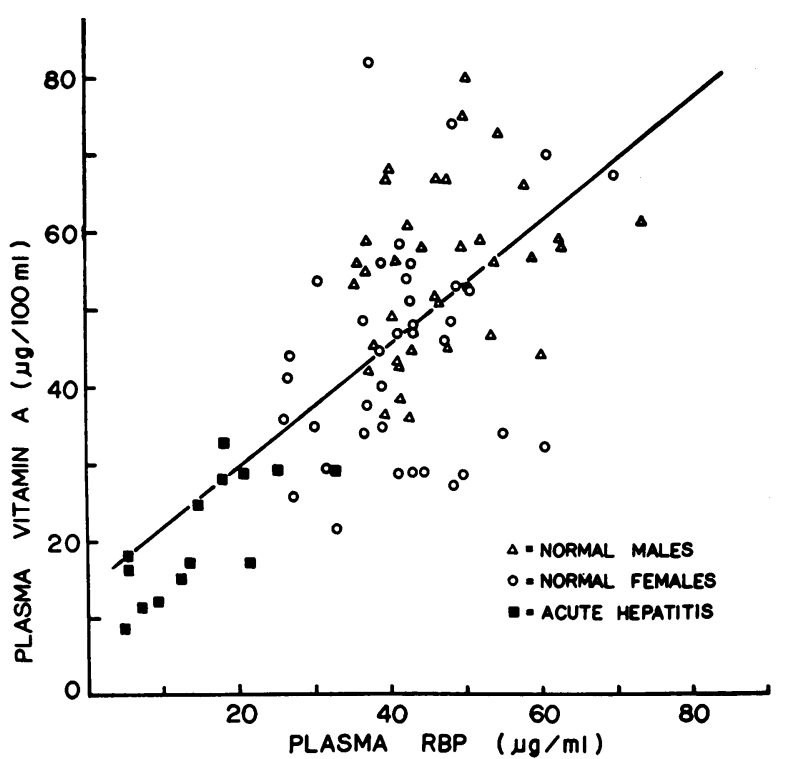

Figure 7 Correlation between plasma RBP and plasma vitamin A concentrations in normal males, normal females, and subjects with acute hepatitis.

The relationship between plasma $\mathrm{RBP}$ and vitamin $\mathrm{A}$ levels can also be examined by estimating the extent to which RBP in plasma is saturated with retinol. Since each RBP molecule can bind and transport a single molecule of retinol, it was possible to calculate readily the level of plasma retinol which would be expected for complete saturation of the protein at any given level of RBP. The expected retinol level for complete saturation was then compared with the observed vitamin A level for each sample of plasma. In the normal male subjects the mean saturation of RBP with retinol \pm SD was 88 $\pm 20 \%$ and in the female subjects, $82 \pm 26 \%$. The extent of RBP saturation could not be estimated with comparable reliability in the subjects with hepatitis because of the large relative error inherent in the measurement of very low levels of vitamin A in plasma. The data (see Fig. 7) suggest, however, that RBP was fully saturated with retinol in these patients.

\section{DISCUSSION}

A radioimmunoassay has been developed to measure accurately the level of RBP in human plasma. The immunoassay is specific for RBP and has a fairly high degree of quantitative precision (reproducibility) and reliability. The specificity of the radioimmunoassay was studied by demonstrating that the RBP- ${ }^{181} \mathrm{I}$ was completely $(>95 \%)$ immunoprecipitable in the presence of an excess of specific antiserum, that it was not $(<5 \%)$ immunoprecipitable in the absence of specific antibody, and that the RBP-181 I could be almost completely displaced from antibody by excess unlabeled purified RBP.
Control tubes examining each of these characteristics were included with each set of assays. Samples were routinely assayed in duplicate, with individual values differing by $5 \pm 5 \%$ (mean $\pm S D$ ) from the mean value for each duplicate pair. The repeated analysis of a single sample of plasma during a 6 month period gave values varying from their mean by $\pm 8 \%$ (SD). The results appear to be reliable since there was a quantitative recovery of purified RBP added in varying amounts to normal plasma. The immunoassay accurately measures RBP in the amounts of $10-100 \mathrm{ng}$ per assay tube. The sensitivity of the assay is such that normal plasma must be extensively diluted before assay with the addition of the equivalent of approximately $1 \mu 1$ of plasma per assay tube.

It was reported previously that purified RBP did not react with commercial antisera against whole human serum or against a variety of individual human serum proteins including prealbumin (1). The finding that RBP failed to react with anti-human whole serum antiserum suggested that RBP might be a relatively poor antigen compared to most other serum proteins. The results presented here demonstrate, however, that purified $\mathrm{RBP}$ is an effective antigen and that an antiserum specific for $R B P$ can be prepared in rabbits by conventional procedures. RBP appears to be immunologically distinct from other known serum proteins.

As discussed above, purified RBP is microheterogeneous on disc-gel electrophoresis and consists of three bands, two fluorescent and one nonfluorescent (3). Since the purified RBP used for immunizing rabbits, for iodination, and for standard solutions in the immunoassay was a mixture of these three components, it was important to determine whether the subspecies differed in their immunoreactivity in the assay. If there were significant variation, for example, the assay might not measure accurately the total level of RBP in subjects with varying proportions of holo- and apoprotein circulating in their plasma. The immunoreactivity of apo$\mathrm{RBP}$, prepared by heptane extraction of retinol from RBP or isolated after prolonged handling and purification, was compared with that of the standard RBP as well as with that of the isolated holo-RBP subspecies. There were no significant differences in the immunoreactivity of the apo- as compared to the holo-RBP or among the different RBP subspecies. It was previously suggested (3) that during purification the naturally occurring form of holo-RBP is converted to a more rapidly migrating form of the holoprotein and, in turn, to the apoprotein. The results presented here indicate that the total amount of RBP in plasma would be determined accurately in the immunoassay regardless of the proportions of the different subspecies present at the time of assay. 
Using the radioimmunoassay, the mean plasma RBP values ( \pm SEM) for a group of 76 normal subjects were $47.2 \pm 1.6 \mu \mathrm{g} / \mathrm{ml}$ for males and $41.6 \pm 1.6 \mu \mathrm{g} / \mathrm{ml}$ for females. The females were not on contraceptive medication, and there was no correlation between RBP levels and age in these groups. The mean RBP level in this group of males was significantly higher than in the females. Patients in the early phase of acute viral hepatitis showed a marked depression of their plasma RBP levels. It is likely that this depression resulted from a decreased rate of RBP synthesis and secretion by the diseased liver. Although direct evidence for the synthesis and secretion of RBP in the liver is not available, indirect evidence for this conclusion includes the fact that vitamin A is mainly stored in (and can be mobilized readily from) the liver (14), as well as these findings in patients with hepatitis. Studies are currently in progress to further define the effects of liver disease on the levels and metabolism of RBP and to examine the pathophysiological consequences of such effects.

A highly significant correlation was found between the plasma levels of RBP and of vitamin A in both the healthy subjects and the patients with hepatitis. The absolute levels of $\mathrm{RBP}$ and vitamin $\mathrm{A}$ were such that the two components were generally present in nearly equimolar amounts with a mean molar ratio (vitamin $A / R B P$ ) in the normal subjects of 0.85 . The findings suggest that a small amount of apo-RBP may normally circulate in plasma in some subjects, although the combined absolute errors in the methods for assaying $\mathrm{RBP}$ and vitamin A make this conclusion an uncertain one. The results indicate, however, that in this group of subjects plasma RBP was generally saturated with retinol, and the data suggest that under normal circumstances RBP circulates almost exclusively in the form of the holoprotein.

\section{ACKNOWLEDGMENTS}

We thank Mr. T. Shiratori and Miss E. Miller for expert assistance. We are grateful to Doctors A. G. Frantz, C. L. Christian, J. H. Morse, and L. J. Kagan for advice and discussions.
This work was supported in part by Grant AM-05968 from the National Institutes of Health and by Contract No. DADA 17-70-C-0002 from the Department of the Army.

\section{REFERENCES}

1. Kanai, M., A. Raz, and DeW. S. Goodman. 1968. Retinol-binding protein: the transport protein for vitamin A in human plasma. J. Clin. Invest. 47: 2025.

2. Raz, A., and DeW. S. Goodman. 1969. The interaction of thyroxine with human plasma prealbumin and with the prealbumin-retinol-binding protein complex. J. Biol. Chem. 244: 3230.

3. Raz, A., T. Shiratori, and DeW. S. Goodman. 1970. Studies on the protein-protein and protein-ligand interactions involved in retinol transport in plasma. J. Biol. Chem. 245: 1903.

4. Ouchterlony, Ö. 1962. Diffusion-in-gel methods for immunological analysis. In Progress in Allergy. P. Kallos and B. H. Waksman, editors. S. Karger AG, Basel. 6: 30 .

5. McFarlane, A. S. 1964. Metabolism of plasma proteins. In Mammalian Protein Metabolism. H. N. Munro and J. B. Allison, editors. Academic Press, Inc., New York. 1: 331. Appendix XIV.

6. Morgan, C. R., and A. Lazarow. 1963. Immunoassay of insulin: two antibody system. Plasma insulin levels of normal, subdiabetic and diabetic rats. Diabetes. 12: 115.

7. Dugan, R. E., N. A. Frigerio, and J. M. Siebert. 1964. Colorimetric determination of vitamin $\mathrm{A}$ and its derivatives with trifluoroacetic acid. Anal. Chem. 36: 114.

8. Roels, O., and S. Mahadevan. 1967. Vitamin A. In The Vitamins. P. Gyorgy and W. N. Pearson, editors. Academic Press, Inc., New York. 2nd edition. 6: 156.

9. Olivetti Underwood Programma 101, Statistical Analysis Manual. 1969. J. B. Williams, editor. 68-71.

10. Snedecor, G. W., and W. G. Cochran. 1967. Statistical Methods. Iowa State University Press, Ames. 6th edition. 184.

11. Graber, P., and C. A. Williams, Jr. 1955. Méthode Immuno-Electrophorétique D'analyse de mélanges de substances antigéniques. Biochim. Biophys. Acto. 17: 67.

12. Havel, R. J., H. A. Eder, and J. H. Bragdon. 1955. The distribution and chemical composition of ultracentrifugally separated lipoproteins in human sera. J. Clin. Invest. 34: 1345.

13. Goodman, DeW. S. 1969. Retinol transport in human plasma. Amer. J. Clin. Nutr. 22: 911.

14. Moore, T. 1957. Vitamin A. Elsevier Publishing Company, New York. 208. 